\title{
RANCANG BANGUN PERANGKAT LUNAK BILLING DAN IMPLEMENTASI VOICE OVER INTERNET PROTOCOL
}

\author{
Honni \\ Information Systems Department, School of Information Systems, Binus University \\ Jl. K.H. Syahdan No. 9, Palmerah, Jakarta Barat 11480 \\ honni@binus.edu
}

\begin{abstract}
The rapidly evolving communication system enables applications for telephone communication to be carried over the data network known as VoIP (voice over internet protocol). SIP (session initiation protocol) as the signaling protocol is text-based VoIP which can be implemented easily in comparison with other signaling protocols. The purpose of this paper is designing and implementing VoIP billing up to the company to provide additional facilities for enterprise customers. The methods start with data collection, analysis, design, development, and implementation. The result achieved is a system of VoIP with SIP and Asterisk software which has functions of PBX to provide additional facilities such as VoIP which is a plus for the company and customers. After implemented, the VoIP system and billing features are found work well.
\end{abstract}

Keywords: billing, VoIP, PBX, SIP

\begin{abstract}
ABSTRAK
Sistem komunikasi yang berkembang pesat telah memungkinkan aplikasi untuk komunikasi telepon dilakukan melalui jaringan data yang dikenal dengan istilah VoIP (voice over internet protocol). SIP (session initiation protocol) sebagai protokol signaling VoIP yang berbasis teks dapat diimplementasikan dengan mudah dibandingkan dengan protokol signaling lainnya. Tujuan dari makalah ini adalah merancang bangun billing dan implementasi VoIP pada perusahaan untuk memberikan fasilitas tambahan bagi pelanggan perusahaan. Metode yang digunakan dimulai dengan mengumpulkan data, analisis, perancangan, pengembangan, dan implementasi. Hasil yang ingin dicapai adalah suatu sistem VoIP dengan protokol SIP dan software Asterisk yang mempunyai fungsi-fungsi PBX untuk memberikan fasilitas tambahan berupa VoIP yang merupakan nilai tambah bagi perusahaan dan bagi pelanggannya. Simpulan yang diperoleh adalah sistem VoIP dan fitur billing berjalan dengan baik.
\end{abstract}

Kata kunci: Billing, VoIP, PBX, SIP 


\section{PENDAHULUAN}

Kebutuhan akan komunikasi dalam skala global dengan biaya murah serta ketersediaan infrastruktur mendorong perkembangan yang cukup pesat akan teknologi komunikasi digital melalui prasarana komunikasi data (VoIP). Di sisi lain, komunikasi dengan sistem PBX untuk bisnis skala kecil hingga enterprise saat ini masih banyak menggunakan jaringan telepon PSTN yang memerlukan biaya yang cukup mahal dalam komunikasi.

PBX (private branch exchange) adalah perangkat yang menghubungkan telepon-telepon dalam suatu jaringan lokal dengan jaringan telepon umum. Voice over Internet Protocol (VoIP) atau IP Telephony adalah teknologi yang memanfaatkan Internet Protocol untuk menyediakan komunikasi voice jarak jauh secara elektronis dan realtime. Signaling Protocol dalam VoIP digunakan untuk membangun atau memutuskan sesi komunikasi, menyimpan informasi mengenai letak user, dan menegosiasikan kapabilitas. SIP (session initiation protocol) adalah signaling protocol untuk menciptakan, mengatur dan menghentikan sesi komunikasi multimedia antara dua atau lebih peserta. Fungsi SIP antara lain: call initiation, call modification, call termination, dan presence. Komponen SIP terdiri dari SIP Server (meliputi proxy server, registrar server, dan redirect server) dan SIP User Agent (hardphone maupun softphone). Untuk menghubungkan antara SIP dengan PSTN, digunakan media gateway. Coder-Decoder atau Codec merupakan sebuah teknik untuk memetakan suara analog yang telah disampling ke dalam bentuk digital. Agar dapat melewati jalur packet switch dengan baik, VoIP membutuhkan proses coder dan decoder. Softswitch bertugas menampung seluruh data alamat IP dan nomor telepon (extension) yang ada untuk kemudian dihubungkan satu dengan yang lainnya membentuk interkoneksi yang lebih besar. Asterisk merupakan software PBX open source yang dapat dijalankan pada berbagai sistem operasi. Fitur billing pada VoIP merupakan aplikasi yang menghasilkan catatan mengenai jumlah tagihan pemakaian telepon dari customer (Davidson, 2006; Johnston, 2006).

Maka dari itu, penelitian ini bertujuan untuk merancang VoIP server dengan protokol SIP, merancang user interface bagi admin (administrasi VoIP server) bagi user (mengakses detil komunikasi dan billing), dan merancang sistem billing untuk pemakaian jasa komunikasi VoIP bagi perusahaan.

Ruang lingkupnya adalah instalasi dan konfigurasi VoIP server Asterisk dengan protokol SIP menggunakan koneksi jaringan lokal (LAN) internet (WAN) dan PSTN, perancangan user interface untuk admin (administrasi VoIP server) dan user (mengakses detil komunikasi dan billing), pembuatan program sistem billing dengan metode postpaid pada VoIP server, dan implementasi sistem Asterisk PBX pada perusahaan.

Manfaat yang diperoleh adalah dapat lebih memahami cara kerja jaringan VoIP terutama yang berbasis SIP, kemudahan administrasi pada VoIP server dan memudahkan user untuk mengetahui informasi tentang penggunaan VoIP, meningkatkan kinerja perusahaan terutama dalam hal telekomunikasi, sebagai nilai tambah (fasilitas tambahan) bagi pelanggan, dan sebagai dasar pengembangan VoIP server pada skala yang lebih luas, misalnya sebagai VoIP service provider.

\section{METODE}

Metode yang digunakan dimulai dengan mengumpulkan data, analisis, perancangan, pengembangan, dan implementasi. 


\section{HASIL DAN PEMBAHASAN}

Beberapa hal penting yang ditemukan adalah pertama, sistem PBX di perusahaan hanya digunakan untuk komunikasi internal perusahaan. Kedua, perusahaan berencana mengembangkan bisnis di bidang VoIP. Ketiga, perusahaan berencana memberikan fasilitas VoIP sebagai fasilitas tambahan pelanggan yang berlangganan ISP pada perusahaan. Keempat, perusahaan juga memerlukan sistem billing untuk menghitung biaya VoIP bagi pengguna yang tidak berlangganan ISP pada perusahaan.

Berdasarkan Gambar 1 terlihat bahwa perusahaan akan menambah satu server VoIP berbasis Asterisk untuk menyediakan fasilitas VoIP bagi pelanggan perusahaan.

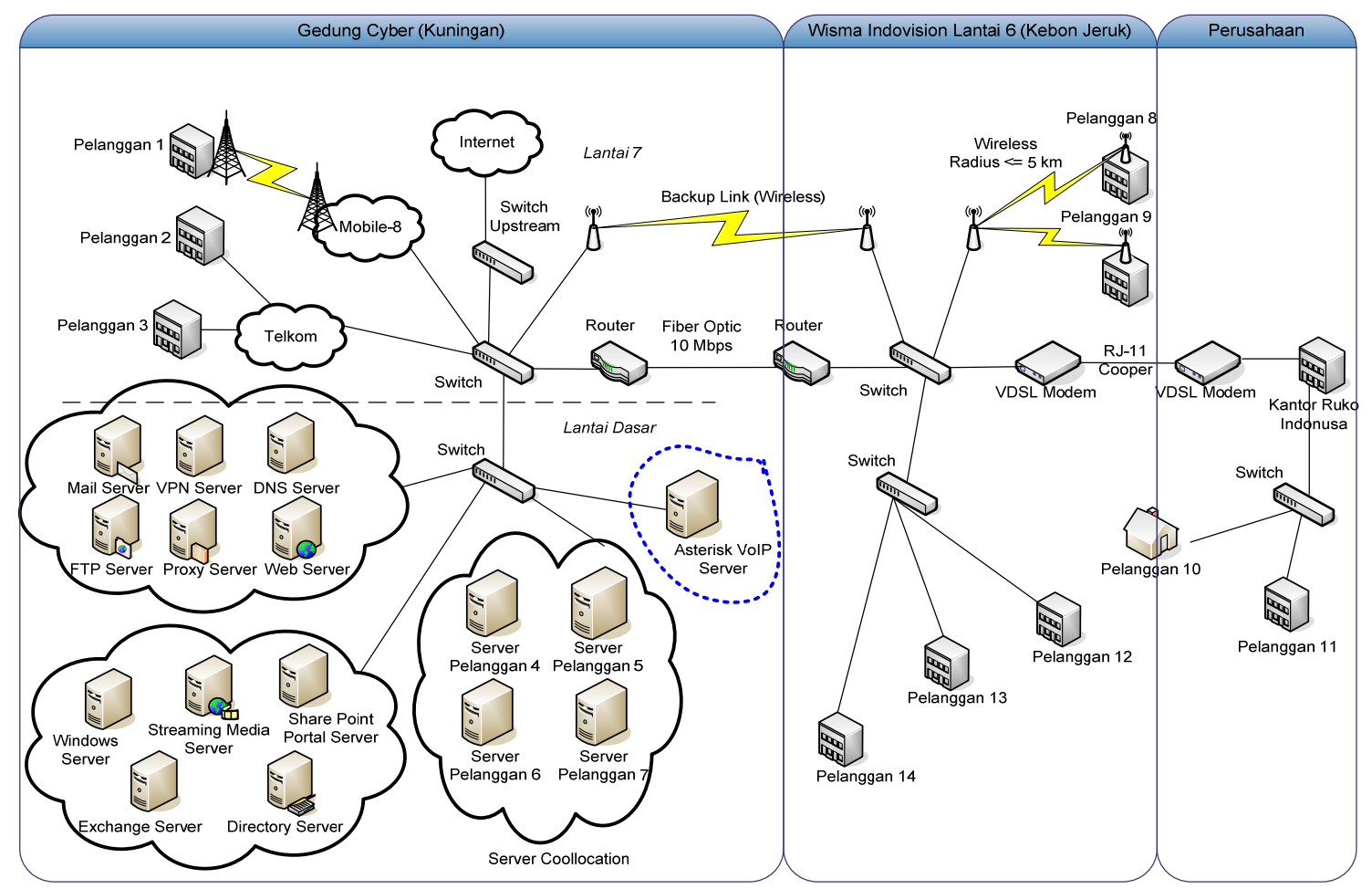

Gambar 1 Topologi jaringan perusahaan yang akan datang

Sistem VoIP PBX yang dirancang (Gambar 2) terdiri dari komponen SIP Server (SIP Redirect Server, SIP Registrar Server, dan SIP Proxy Server), Database Server, dan Web Server.

Komponen SIP server berfungsi sebagai VoIP PBX yang melakukan registrasi user, panggilan, maupun pengalihan ke server lain. Komponen SIP server yang dirancang menggunakan sistem yang telah ada pada Asterisk dan dikonfigurasi sedemikian rupa sehingga dapat berfungsi dengan baik.

Database server merupakan penyedia database user, extension, sehingga SIP server mengambil data dari server tersebut. Database server yang dirancang menggunakan database default dari sistem Asterisk, serta dilakukan penambahan tabel baru pada database untuk menyimpan datadata client dan mendukung sistem billing yang dirancang. Web server yang dirancang menyediakan tampilan antarmuka sebagai penghubung antara database server dengan administrator SIP server. 
Media Gateway menyediakan koneksi dari VoIP (SIP) ke jalur PSTN, sehingga user agent dapat melakukan panggilan ke luar menggunakan jaringan PSTN yang ada.

Protokol signaling yang digunakan adalah SIP dalam komunikasi antara VoIP server dengan client-nya, antara VoIP server dengan PBX lain dan antara VoIP server dengan media gateway. Untuk protokol media transfer yang digunakan dalam komunikasi antar client adalah RTP yang berbasis UDP.

Sistem VoIP yang dirancang ini memiliki fitur-fitur realtime meliputi SIP, Extension, Call Detail Record (CDR), Voice Mail, Billing, dan Agi Manager.

Perangkat keras yang dipilih untuk sistem VoIP server ini menggunakan satu komputer server yang mencakup SIP proxy server, SIP registrar server, SIP redirect server, database server, dan web server. Untuk SIP user agent, digunakan SIP Phone atau USB Phone yang mendukung SIP dan komputer yang telah diinstalasi dengan softphone. Media gateway yang digunakan dalam perancangan ini adalah AudioCodes MP-114 FXO.

Pemilihan perangkat lunak meliputi sistem operasi, software VoIP server, aplikasi database dan web. Sistem operasi yang digunakan pada server yaitu Linux. Untuk SIP proxy server, SIP registrar server, dan SIP redirect server, software yang digunakan adalah Asterisk. Database server yang digunakan adalah MySQL. Aplikasi yang digunakan pada pembuatan halaman web pada web server untuk administrasi melalui web adalah dengan Apache Tomcat. Untuk scripting web menggunakan bahasa pemrograman JSP. Gambar 3 menunjukkan stuktur menu dari SIP Asterisk Web Portal yang dirancang.

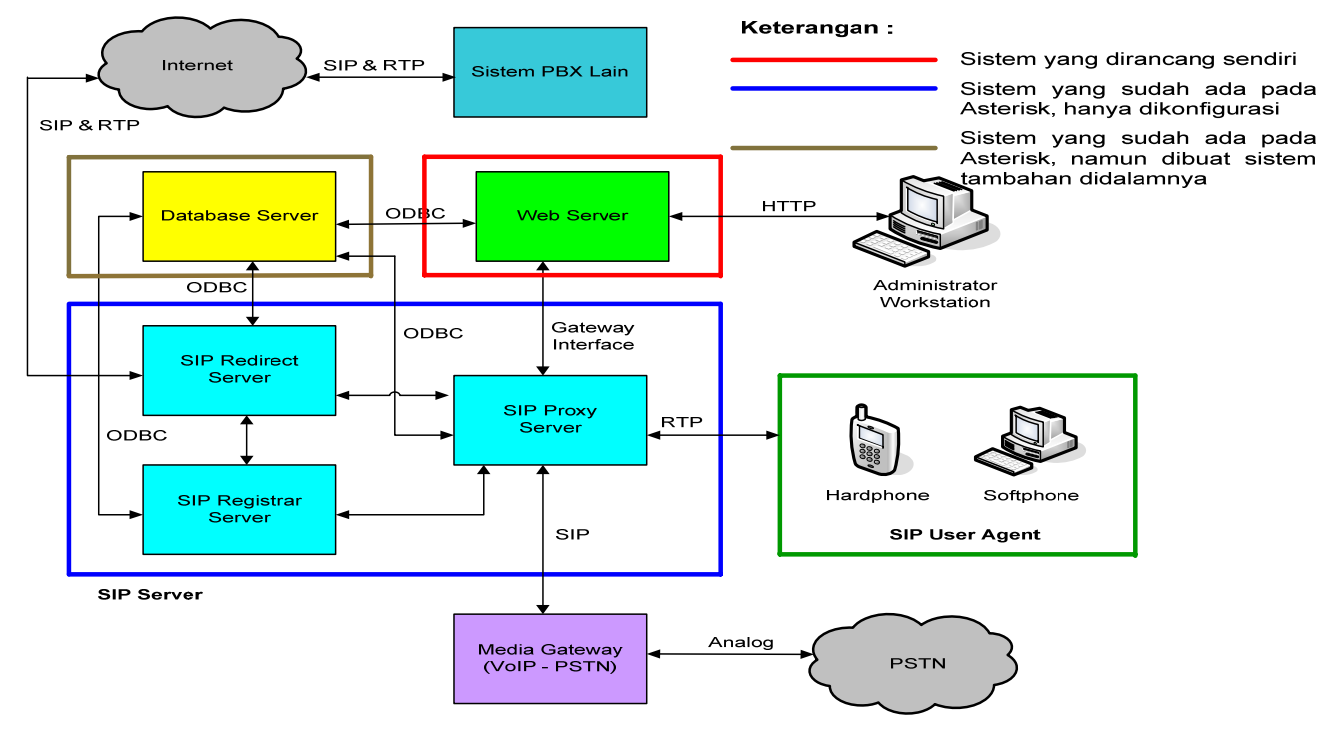

Gambar 2 Rancangan Sistem VoIP SIP PBX

Struktur menu web portal yang dirancang terdiri dari menu-menu: Login, Admin (User Profile, Add New SIP, Show SIP, Add New Extension, Show Extension, Voice Mail, CDR, Billing, dan Agi Man), User (CDR, Billing, Contact Us, Change Password), dan Logout. Rancangan STD menggambarkan hubungan antara halaman/menu yang satu dengan yang lainnya serta transisi yang menggambarkan hubungan antar halaman/menu. Gambar 4 merupakan contoh STD dari halaman/menu Add New SIP. 


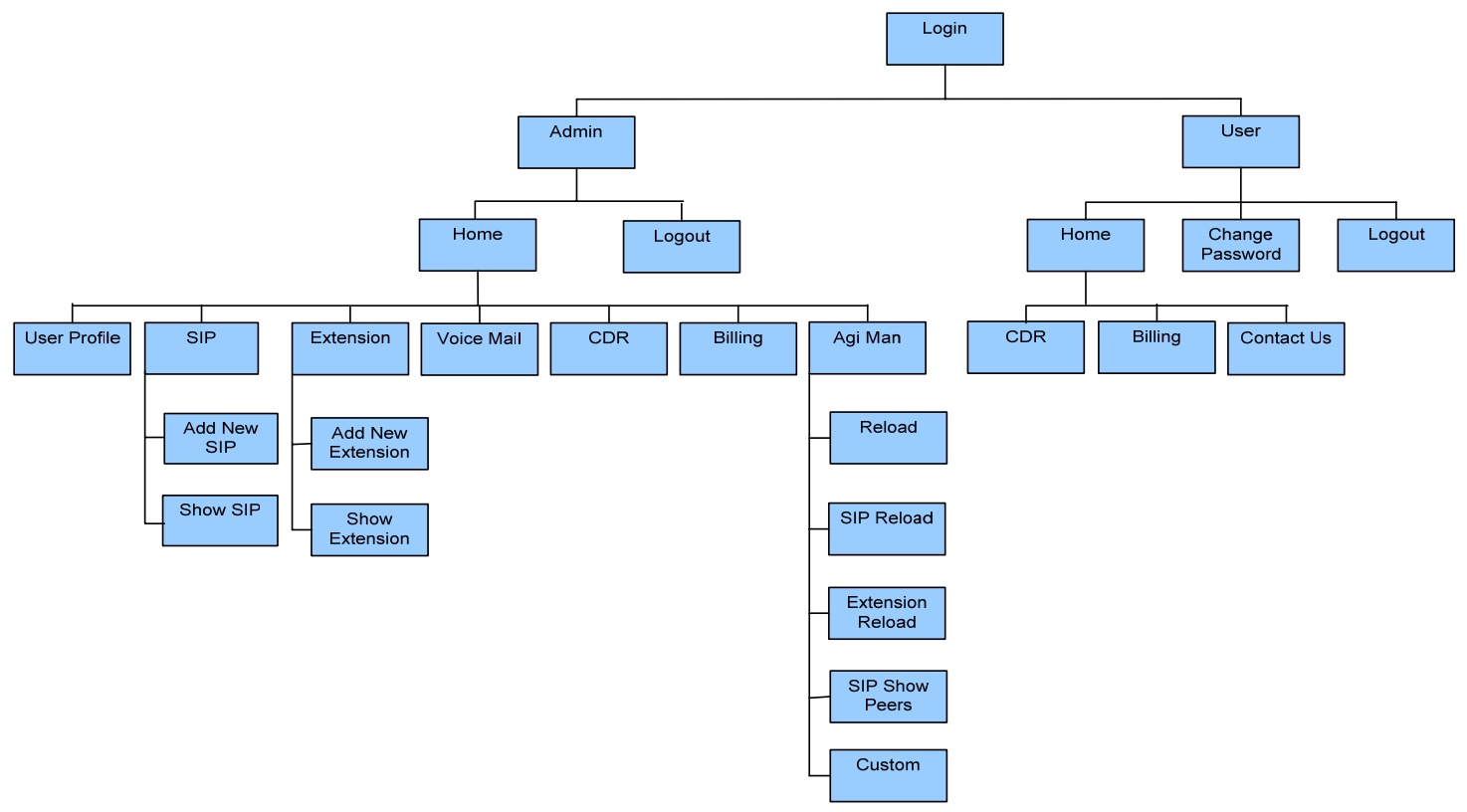

Gambar 3 Rancangan Struktur Menu SIP Asterisk Web Portal

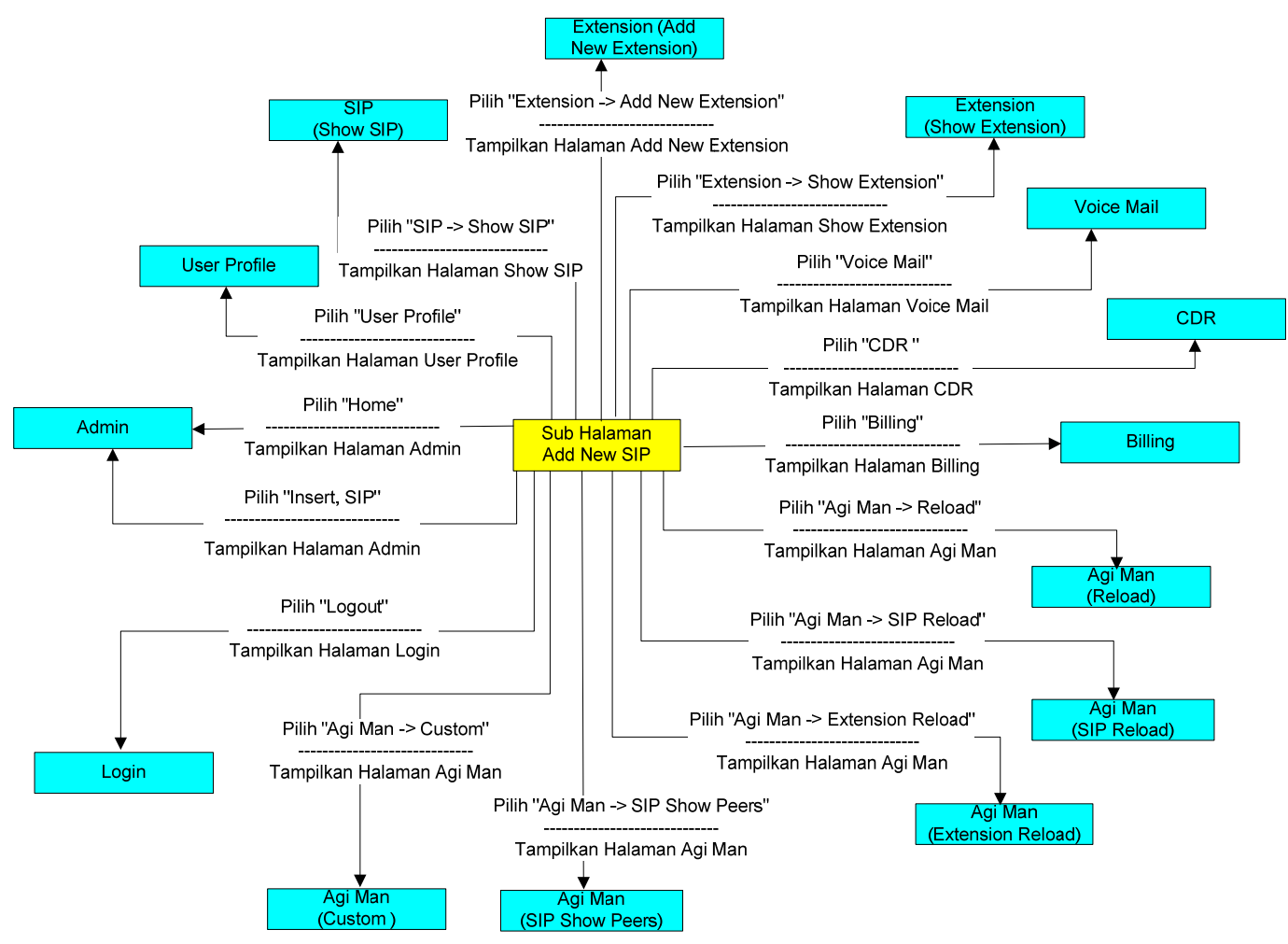

Gambar 4 Rancangan STD Add New SIP

Web portal ini mengakses satu database yang bernama asterisk. Database yang telah ada pada sistem Asterisk terdiri dari tabel-tabel: SIP, Extension, Voice mail, CDR. Selain itu, tabel database yang ditambahkan untuk mendukung sistem yang dirancang antara lain: Master User, Area Code. 
Antar muka pemakai (user interface) pada sistem ini yaitu tampilan layar pada web browser. Pada rancangan layar, dibuat storyboard pada setiap halaman menurut struktur menu sehingga desain akan lebih terarah. Gambar 5 merupakan contoh rancangan layar dari halaman Add New SIP.

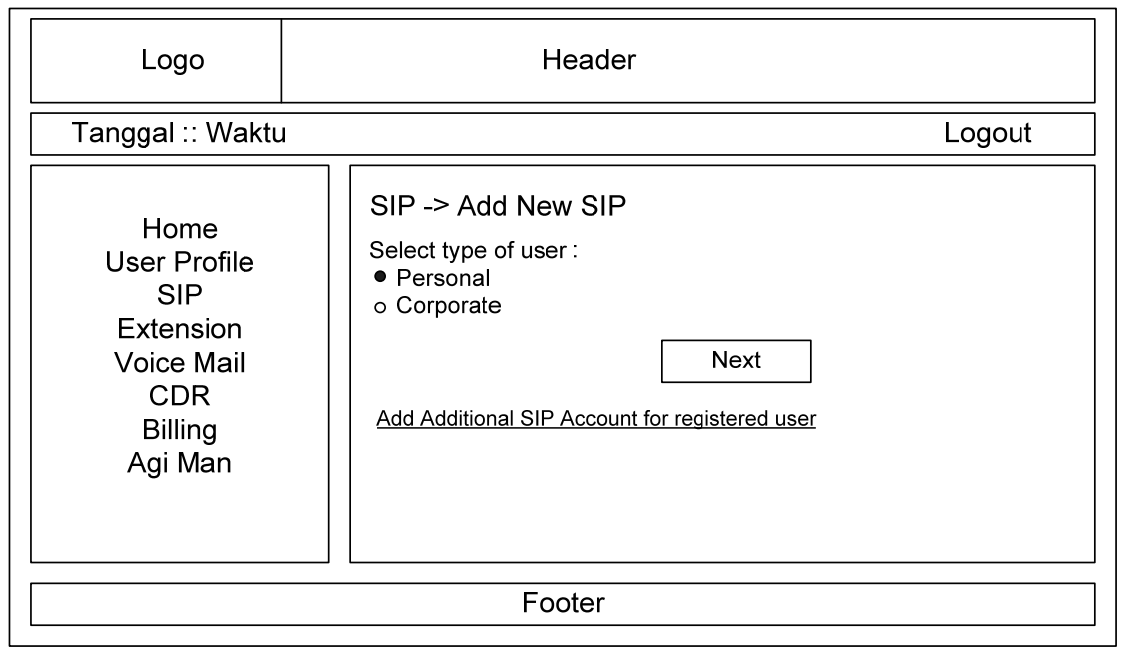

Gambar 5 Rancangan Layar Add New SIP

Program Asterisk dapat dijalankan baik secara background atau console. Untuk menjalankan server secara background, maka perintahnya adalah: \# asterisk (tanda \# merupakan representasi prompt terminal di Linux) sedangkan untuk menjalankan server secara console perintahnya adalah: \# asterisk -c.

Sistem konfigurasi pada Asterisk terdapat pada file konfigurasi yang memiliki ekstensi .conf. Lokasi file-file dan direktori pada Asterisk antara lain: (1) /etc/asterisk: konfigurasi utama; (2) /var/log/asterisk: log dan call detail record (CDR); (3) /var/lib/asterisk: aplikasi dan data pendukung (AGI, sounds); (4) /usr/lib/asterisk: codec dan aplikasi; (5) /etc/asterisk/sip.conf: data account extension (menggunakan SIP); (6) /etc/asterisk/extensions.conf: data dialplan.

SIP Asterisk Web Portal yang dirancang terdiri dari dua pengguna yaitu admin (administrasi VoIP server) dan client (melihat detil komunikasi dan billing). Gambar 6 merupakan contoh tampilan halaman web pada admin (penyedia VoIP server) dan Gambar 7 merupakan contoh tampilan halaman web pada user (client pengguna VoIP).

Pengujian sistem dilakukan pada empat macam jaringan: (1) jaringan lokal (LAN) - untuk menguji fungsi telepon antar extension dan fungsi PBX oleh user dalam LAN. Hasil pengujian yaitu fungsi telepon berjalan normal dan kualitas suara yang dihasilkan jelas. Pemilihan codec tidak terlalu diperhatikan; (2) jaringan internet (NAT) - untuk menguji fungsi telepon antar extension dan fungsi PBX oleh user dalam NAT. Hasil pengujian yaitu komunikasi dengan menggunakan codec yang berbandwidth rendah (iLBC dan GSM) berjalan dengan baik (suara jelas). Sedangkan komunikasi dengan codec berbandwidth besar (G711A dan G711U) tidak berjalan dengan baik (suara tidak jelas); (3) jaringan PSTN - untuk menguji fungsi telepon antara hardphone dengan telepon analog/mobile phone melalui jaringan PSTN. Hasil pengujian yaitu komunikasi antara hardphone dengan mobile phone maupun komunikasi antara telepon analog dengan hardphone melalui PSTN, keduanya berjalan dengan baik (suara jelas); (4) sistem billing - untuk menguji sistem billing pada admin dan user. Hasil pengujian yaitu pengujian billing user (personal dan corporate) dan billing admin berjalan dengan baik (perhitungan yang dilakukan sudah tepat). Fitur print to file pada billing user juga berjalan dengan baik. 


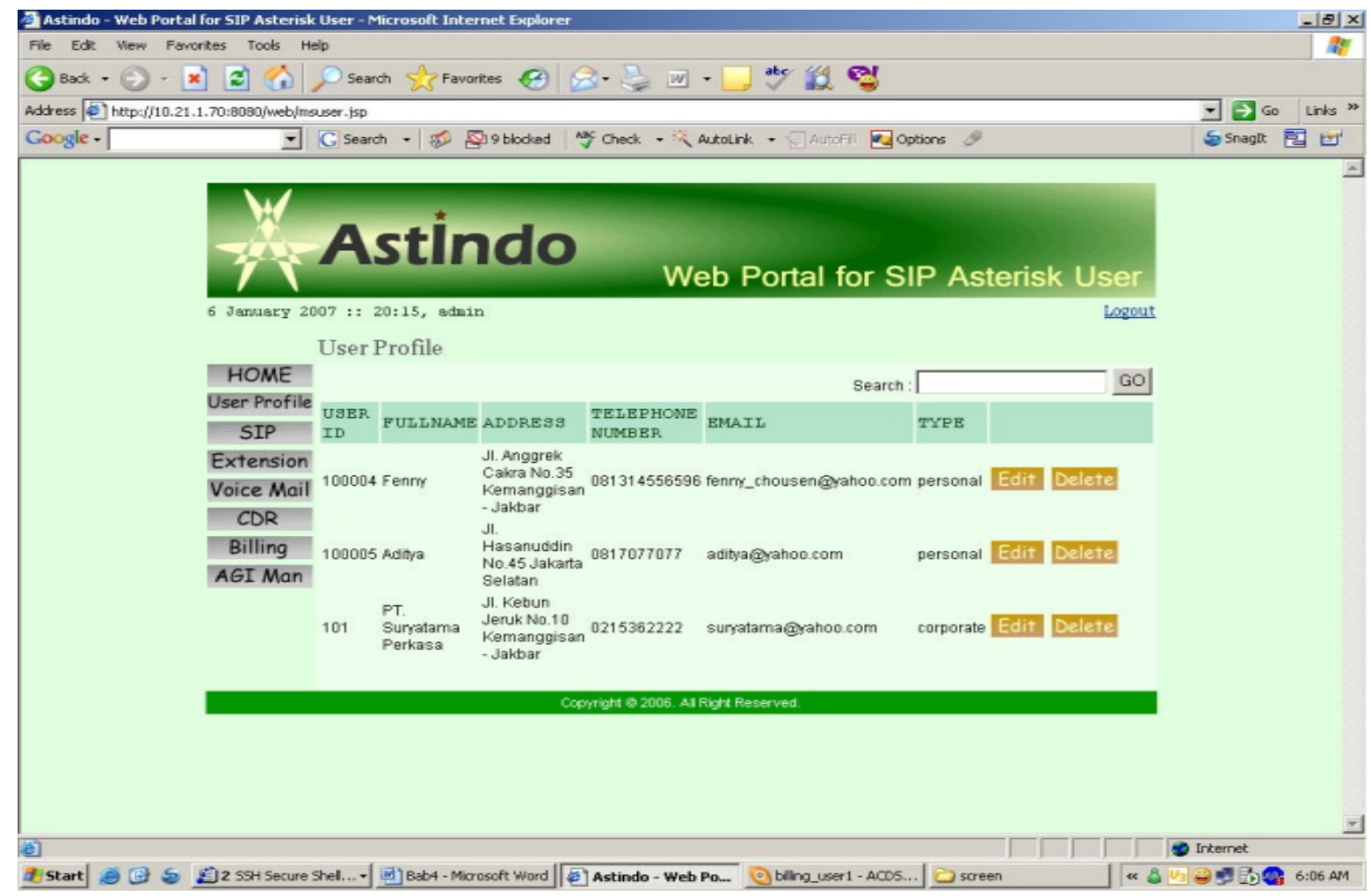

Gambar 6 Halaman User Profile (Admin)

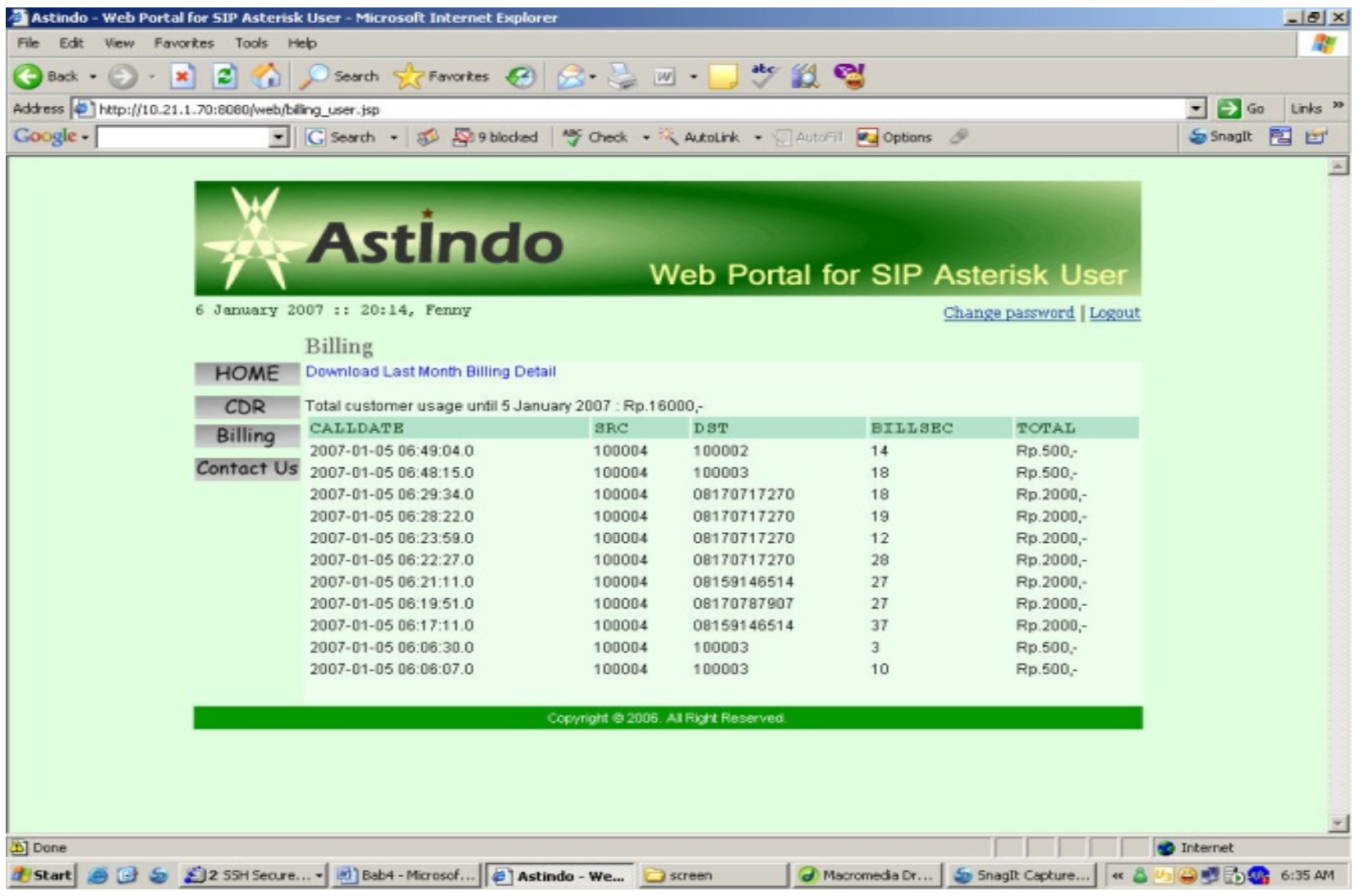

Gambar 7 Halaman Billing User Personal (User) 
Evaluasi sistem pada web interface semuanya berfungsi dengan baik karena sudah memenuhi dan sesuai dengan kaidah-kaidah interaksi manusia dan komputer. Pada sistem billing, sistem pemilihan record dari database CDR yang perlu dihitung berjalan dengan baik. Sistem perhitungan biaya sesuai dengan harga yang telah ditentukan. Fitur penulisan (print to file) berjalan dengan baik. Evaluasi perbandingan harga dan sistem dapat dilihat pada Tabel 1 berikut ini:

Tabel 1 Perbandingan Asterisk dan PBX Lain

\begin{tabular}{|c|c|c|c|}
\hline $\begin{array}{c}\text { Hal } \\
\text { Perbandingan }\end{array}$ & $\begin{array}{c}\text { Asterisk PBX } \\
\text { (Software) }\end{array}$ & $\begin{array}{c}\text { Alcatel } \\
\text { OmniPCX } \\
\text { Office } \\
\text { (Hardware) }\end{array}$ & $\begin{array}{l}\text { AGEPhone } \\
\text { (Software) }\end{array}$ \\
\hline $\begin{array}{l}\text { Biaya } \\
\text { Hardware }\end{array}$ & $\begin{array}{r}\text { Rp. 13.588.435,- } \\
\text { (PC Server) } \\
\text { Rp. 3.988.147,- } \\
\text { (Media Gateway) }\end{array}$ & Rp. 49.529.210,- & $\begin{array}{r}\text { Rp. 13.588.435,- } \\
\text { (PC Server) } \\
\text { Rp. 3.988.147,- } \\
\text { (Media Gateway) }\end{array}$ \\
\hline $\begin{array}{l}\text { Biaya } \\
\text { Software }\end{array}$ & $\begin{array}{l}\text { Gratis (Linux + } \\
\text { Asterisk) }\end{array}$ & Tidak Ada & $\begin{array}{r}\text { Rp.1.500.000,- } \\
\text { (Windows XP), } \\
\text { Rp. 453.250,- } \\
\text { (AGEPhone) }\end{array}$ \\
\hline $\begin{array}{l}\text { Biaya Gaji } \\
\text { Admin }\end{array}$ & $\begin{array}{r}\text { Rp. 2.000.000,- } \\
\text { perbulan } \\
\end{array}$ & $\begin{array}{r}\text { Rp. 2.000.000,- } \\
\text { perbulan } \\
\end{array}$ & $\begin{array}{r}\text { Rp. 2.000.000,- } \\
\text { perbulan } \\
\end{array}$ \\
\hline $\begin{array}{l}\text { Biaya } \\
\text { Training }\end{array}$ & Rp. 2.000.000,- & Rp. 10.000.000,- & Rp. 700.000,- \\
\hline $\begin{array}{l}\text { Client: } \\
\text { SIP/IP Phone }\end{array}$ & $\begin{array}{r}\text { Rp. 815.397,- } \\
\text { (per unit) }\end{array}$ & $\begin{array}{l}\text { Sudah termasuk } \\
\text { pembelian }\end{array}$ & $\begin{array}{r}\text { Rp. 815.397,- } \\
\text { (per unit) }\end{array}$ \\
\hline $\begin{array}{l}\text { Jumlah } \\
\text { Concurrent } \\
\text { Users }\end{array}$ & $\begin{array}{l}70 \text { concurrent } \\
\text { users } \\
\text { (tergantung } \\
\text { spesifikasi } \\
\text { server) }\end{array}$ & $\begin{array}{l}20 \text { concurrent } \\
\text { users } \\
\text { (sama dengan jumlah } \\
\text { port pada } \\
\text { hardware) }\end{array}$ & $\begin{array}{l}35 \text { concurrent } \\
\text { users } \\
\text { (tergantung } \\
\text { spesifikasi } \\
\text { server) }\end{array}$ \\
\hline Total & Rp. 22.391.979, & Rp. 61.529.210,- & Rp. 23.045.229 \\
\hline
\end{tabular}

\section{PENUTUP}

Beberapa kesimpulan yang diperoleh yaitu penggunaan bandwitdh untuk VoIP tergantung pada codec yang digunakan. VoIP memiliki fitur penggunaan telepon dengan menggunakan extension seperti pada PBX konvensional. Kualitas suara yang dihasilkan oleh VoIP tergantung dari codec dan bandwidth yang digunakan. Komunikasi antara VoIP dan PSTN melalui media gateway sebagai penghubung antar kedua teknologi yang berbeda tersebut. Jumlah maksimum komunikasi tergantung pada spesifikasi komputer server dan bandwith yang tersedia. Penggunaan server lebih mudah dengan bantuan web interface.

Adapun beberapa sarannya adalah pengembangan sistem VoIP dalam skala yang lebih besar, misalkan VoIP Service Provider. Pengembangan sistem billing lebih kompleks, dibagi berdasarkan penggunaan prepaid dan postpaid. Penerapan sistem monitoring pada sistem VoIP untuk memudahkan pengecekan error. Penerapan sistem keamanan (security) pada sistem VoIP untuk meningkatkan keamanan dalam berkomunikasi melalui internet (NAT). 


\section{DAFTAR PUSTAKA}

Davidson, Jonathan. (2006). Voice over IP Fundamentals (2nd edition). Indiana: Cisco Press.

Johnston, Alan B. (2006). Internet Communications Using SIP Delivering VoIP and Multimedia Services with Session Initiation Protocol. New Jersey: John Wiley and Sons. 